\title{
Reporting of interventions used in cardiothoracic surgery trials: analysis using the Template for Intervention Description and Replication (TIDieR) checklist
}

\author{
Craig Beavers $^{1 *}\left(\mathbb{D}\right.$, Jessica Sosio ${ }^{2}$, Samuel Jellison ${ }^{1}$ and Matt Vassar ${ }^{1}$
}

To the editor,

Randomized controlled trials (RCTs) are the gold standard for evaluating intervention effectiveness [1] and advancing clinical practice in cardiothoracic surgery. Considering the importance of RCTs in cardiothoracic surgery, it is important that RCTs be reported in a thorough, clear, and complete manner. In this study, we evaluated the completeness of intervention reporting of cardiothoracic surgery RCTs using the Template for Intervention Reporting (TIDieR) checklist [2].

Our sample included trials published before the 20112013 and after 2016-2018 publication of the TIDieR checklist from the top 20 cardiothoracic surgery journals as ranked by Google Scholar h5-index. Title/abstract screening, evaluation of TIDieR adherence, and data extraction were performed by two investigators independently.

In 170 analyzed trials, the mean number of TIDieR items reported was 7.4 $(\mathrm{SD}=1.2)$ out of 12 . Five items were completely reported $>80 \%$ of the time and included (1) a brief description of the intervention, (2) the rationale for intervention, (3) a description of activities/ processes used in the intervention, (4) a description of the mode of delivery and if it was provided individually or in a group, and (5) the number of times the intervention was delivered and over what period of time. Three items were reported in fewer than $20 \%$ of the trials including (1) whether modifications were made to the intervention, (2) fidelity assessment (planned), and (3) fidelity assessment (reality). Table 1 presents the results per TIDieR item for all analyzed trials. No included trials provided sufficient intervention description to fulfill all 12 TIDieR items.

Our findings suggest incomplete reporting of RCTs published in cardiothoracic surgery journals. Complete reporting is important to allow for replication of the intervention in future trials, for physicians to implement the intervention into their clinical practice, and for systematic reviewers to have sufficient intervention information to include them for evidence synthesis [3]. The TIDieR checklist was developed to address incomplete reporting. Our results suggest, however, that the publication of TIDieR had no effect on completeness of intervention reporting among trials in our sample. More comprehensive dissemination strategies may be warranted to increase awareness of its existence. Alternatively, TIDieR could be incorporated into the wellestablished CONSORT guideline, the gold standard for reporting clinical trials. Given that CONSORT has a clear gap in intervention reporting guidance, the addition of TIDieR would contribute positively to the CONSORT items. Tiruvoipati et al. [4] reported that only $7.8 \%$ of cardiothoracic trials adequately reported a detailed description of trial setting and location and $26.6 \%$ of included trials provided details of the intervention. Findings from our study, coupled with previous investigations, support the need for improved reporting of cardiothoracic surgery trial interventions.

\footnotetext{
* Correspondence: craig.beavers@okstate.edu

'Oklahoma State University Center for Health Sciences, 1111 W 17th St.,

Tulsa, OK 74107, USA

Full list of author information is available at the end of the article
} 
Table 1 Characteristics of the included studies $(N=170)$

\begin{tabular}{l} 
Journal \\
\hline Annals of Thoracic and Cardiovascular Surgery \\
Asian Cardiovascular and Thoracic Annals \\
Brazilian Journal of Cardiovascular Surgery \\
European Journal of Cardio-thoracic Surgery \\
Innovations: technology and techniques in \\
cardiothoracic and vascular surgery \\
Interactive CardioVascular and Thoracic Surgery \\
Journal of Cardiac Surgery \\
Journal of Cardiothoracic Surgery \\
Perfusion \\
Scandinavian Cardiovascular Journal \\
Seminars in Thoracic and Cardiovascular Surgery \\
The Annals of Thoracic Surgery \\
The Journal of Thoracic and Cardiovascular Surgery \\
The Thoracic and Cardiovascular Surgeon \\
Authors \\
Mean \\
Median \\
Range
\end{tabular}

Hypothesis

Superiority
Equivalence
Other
Non-inferiority
Not sure
Study type
Parallel
Factorial
Other
Crossover
Stepped-wedge
Cluster
Mixed

Intervention

Drug
Table 1 Characteristics of the included studies $(N=170)$

(Continued)

N(\%)

\begin{tabular}{ll}
\hline Journal & $N(\%)$ \\
\hline Procedure & $52(30.6)$ \\
Device & $25(14.7)$ \\
Other & $23(13.5)$ \\
Mixed & $13(7.7)$ \\
Blinding & \\
No-blind & $106(62.4)$ \\
Double-blind & $37(21.8)$ \\
Single-blind & $27(15.9)$ \\
Number of participants & \\
Mean & 132.4 \\
Median & 68 \\
Range & $14-2368$ \\
Country & \\
Outside of USA & $148(87.1)$ \\
USA & $13(7.6)$ \\
Both & $2(1.2)$ \\
Not mentioned & $7(4.1)$
\end{tabular}

No. of conducting centers

Single-center

Multicenter

Authors mention CONSORT

No

137 (80.6)

Yes

33 (19.4)

Authors mention TIDieR

No

$170(100)$

Yes

0

Is the trial registered?

Not registered

Registered

$16(9.4)$

$14(8.2)$

$2(1.2)$

$2(1.2)$

Abbreviations

CONSORT: Consolidated Standards of Reporting Trials; RCT: Randomized controlled trial; SD: Standard deviation; TIDieR: Template for Intervention Description and Replication

\section{Acknowledgements}

161 (94.7) Not applicable

\section{6 (3.5) Authors' contributions}

2 (1.2) CB and JS collected the data and performed the analysis. SJ conceived and designed the analysis. CB and SJ drafted the manuscript and performed critical revision of the manuscript. MV provided oversight of the study. All authors read and approved the final manuscript.

Funding

This investigation was not funded.

Availability of data and materials

The methods, results, and data sets generated and/or analyzed during the current study are available on Open Science Framework, https://osf.io/ hpx9g/ 
Ethics approval and consent to participate

Not applicable

\section{Consent for publication}

Not applicable

\section{Competing interests}

The authors declare that they have no competing interests.

\section{Author details}

'Oklahoma State University Center for Health Sciences, 1111 W 17th St. Tulsa, OK 74107, USA. ${ }^{2}$ Kansas City University of Medicine and Biosciences, 2901 St. John's Boulevard, Joplin, MO 74804, USA.

Received: 20 December 2019 Accepted: 5 February 2020

Published online: 18 February 2020

\section{References}

1. Schulz KF, Altman DG, Moher D (2010) CONSORT 2010 statement: updated guidelines for reporting parallel group randomised trials. BMJ 340:c332

2. Hoffmann TC, Glasziou PP, Boutron I et al (2014) Better reporting of interventions: template for intervention description and replication (TIDieR) checklist and guide. BMJ 348:g1687

3. Agha R, Cooper D, Muir G (2007) The reporting quality of randomised controlled trials in surgery: a systematic review. Int J Surg 5(6):413-422

4. Tiruvoipati R, Balasubramanian SP, Atturu G et al (2006) Improving the quality of reporting randomized controlled trials in cardiothoracic surgery: the way forward. J Thorac Cardiovasc Surg 132(2):233-240

\section{Publisher's Note}

Springer Nature remains neutral with regard to jurisdictional claims in published maps and institutional affiliations.

\section{Submit your manuscript to a SpringerOpen ${ }^{\circ}$ journal and benefit from:}

- Convenient online submission

- Rigorous peer review

- Open access: articles freely available online

- High visibility within the field

- Retaining the copyright to your article 